\title{
К ВОПРОСУ О ЗОНАХ ОХРАНЫ ОБЪЕКТОВ АРХЕОЛОГИЧЕСКОГО НАСЛЕДИЯ НАРОДОВ РОССИЙСКОЙ ФЕДЕРАЦИИ
}

\begin{abstract}
Аннотация. Предметом исследования являются нормы действующего законодательства об объектах культурного наследия, касающиеся зон охраны объектов археологического наследия. Объектом исследования являются общественные отношения, возникающие в ходе определения, установления и утверждения указанных зон охраны, а также их допустимость для объектов археологического наследия. Автором подробно анализируются произошедшие изменения в рассматриваемой части, а также правовое регулирование данного вопроса в субъектах Российской Федерации, выявляется существующая проблема и предлагаются различные пути ее разрешения. В ходе исследования автором использовался комплекс общенаучных методов, таких как дедукция и индукция, анализ и синтез, исторический, социологический. Кроме того, были применены сравнительно-правовой, историко-правовой методы, метод систематического анализа. Новизна исследования заключается в том, что автор на основе историко-правового анализа действующего законодательства, а также логики фактически сложившейся практики анализирует новое положение федерального закона и показывает его ущербность, вызванную не верным толкованием смысла правового института со стороны представителей федерального специализированного органа, после чего предлагает конкретные пути видоизменения или дополнения данного закона в целях выхода из сложившейся ситуации.

Ключевые слова: объект археологического наследия, территория памятника, памятник археологии, зоны охраны, защитные зоны, временные охранные зоны, проект зон охраны, археологический надзор, министерство культуры, толкование нормы.

Abstract. The research subject includes the provisions of the existing legislation on the cultural heritage objects related to the protective zones of archaeological heritage. The research object includes social relations emerging in the process of defining, establishing and approving these protective zones and their appropriateness for the archaeological heritage objects. The author analyzes the changes which had taken place in the legislation under consideration and legal regulation of this issue in the regions of the Russian Federation, detects the existing problem and offers various ways of its solving. The author applies the set of general scientific methods including deduction, induction, analysis, synthesis, the historical and sociological methods, the method of comparative analysis. The novelty of the study consists in the fact that based on the historical and legal analysis of the current legislation and the logic of the established practice, the author analyzes the new provision of the federal law, and demonstrates its defects caused by the incorrect interpretation of the meaning of the legal institution by the representatives of the federal specialized body, and offers the concrete ways of changing or amending this law in order to solve the existing problem.
\end{abstract}

Key words: interpretation of the provision, Ministry of Culture, archaeological supervision, protective zones project, temporary protective zones, protective zones, protective zones, archaeological monument, monument area, archaeological heritage object.

$\mathrm{B}$ соответствии со ст. 44 Конституции Российской Федерации каждый имеет равный доступ к культурным ценностям, обязан заботиться о сохранении исторического и культурного наследия, беречь памятники истории и культуры [1].
Основным нормативно-правовым актом, регулирующим в настоящее время вопрос сохранения исторического и культурного наследия на территории Российской Федерации, является Федеральный закон от 25.06.2002 года № 73-ФЗ «Об объектах культурного наследия (памятниках истории и 
культуры) народов Российской Федерации» (далее - Закон об ОКН) [2].

В ст. 3 вышеуказанного закона дается определение объекта культурного наследия и, в том числе, объекта археологического наследия - «частично или полностью скрытые в земле или под водой следы существования человека в прошлых эпохах (включая все связанные с такими следами археологические предметы и культурные слои), основным или одним из основных источников информации о которых являются археологические раскопки или находки. Объектами археологического наследия являются в том числе городища, курганы, грунтовые могильники, древние погребения, селища, стоянки, каменные изваяния, стелы, наскальные изображения, остатки древних укреплений, производств, каналов, судов, дорог, места совершения древних религиозных обрядов, отнесенные к объектам археологического наследия культурные слои».

В ст. 34 того же закона говорится и о зонах охраны для объектов культурного наследия. При этом как такового понятия зон охраны не дается. Указывается на то, что: «В целях обеспечения сохранности объекта культурного наследия в его исторической среде на сопряженной с ним территории устанавливаются зоны охраны объекта культурного наследия: охранная зона, зона регулирования застройки и хозяйственной деятельности, зона охраняемого природного ландшафта».

Необходимо отметить, что указанное положение было заимствовано из ст. 33 Закона РСФСР от 15.12.1978 года «Об охране и использовании памятников истории и культуры» [3], которое также было продублировано в п. 30 Положения об охране и использовании памятников истории и культуры, утвержденного Постановлением Совета Министров СССР от 16 сентября 1982 г. N 865 [4] и п. 40 Инструкции о порядке учета, обеспечения сохранности, содержания, использования и реставрации недвижимых памятников истории и культуры, утвержденной Приказом Минкультуры СССР от 13.05.1986 № 203 [5]. В указанных нормах содержались аналогичные формулировки и перечисление тех же зон охраны (с небольшими изменениями наименований).

В связи с тем, что состав зон охраны и их режим, разрабатывается и утверждается проектом зон охраны, а порядок разработки и утверждения такового был впервые утвержден Правительством РФ лишь в 2008 году [6], то длительное время для объектов культурного наследия вообще не устанавливались зоны охраны. А учитывая, что финансирование данного мероприятия возложено, в первую очередь, на государственные и муниципальные органы, и, лишь при желании - на физи- ческих и юридических лиц, то до настоящего времени таких проектов зон охраны, а соответственно и самих зон охраны для объектов культурного наследия на территории РФ установлено очень мало (точные сводные данные отсутствуют даже в Министерстве культуры РФ). Таким образом, большинство объектов культурного наследия на сегодняшний день, не имея указанных зон, фактически слабо защищены от возможного негативного влияния в результате нового хозяйственного освоения прилегающих земельных участков, а также активной градостроительной деятельности.

Чтобы хоть как-то исправить данную ситуацию некоторые субъекты РФ (например Краснодарский край), не дожидаясь разрешения вопроса на федеральном уровне, своими законами самостоятельно еще в 2003 году ввели понятие «временные охранные зоны», с установлением их размеров и действием исключительно до разработки и утверждения проектов зон охраны [7].

И вот, проанализировав сложившееся положение, а также практику субъектов РФ, в 2016 году был принят Федеральный закон от 05.04.2016 года № 95-Ф3 «0 внесении изменений в Федеральный закон «Об объектах культурного наследия (памятниках истории и культуры) народов Российской Федерации» и статью 15 Федерального закона «0 государственном кадастре недвижимости» [8], согласно которому в Закон об ОКН была внесена ст. 34.1 «Защитные зоны объектов культурного наследия». В части 1 указанной статьи дается определение защитной зоны объекта культурного наследия - территории, которые прилегают к включенным в реестр памятников и ансамблям и в границах которых в целях обеспечения сохранности объектов культурного наследия и композиционно-видовых связей (панорам) запрещается строительство объектов капитального строительства и их реконструкция, связанная с изменением их параметров (высоты, количества этажей, площади), за исключением строительства и реконструкции линейных объектов. Устанавливаются размеры таких защитных зон. Данные защитные зоны вводятся временно до разработки и утверждения проектов зон охраны, т.е. фактически они должны решать остро стоящую вышеописанную проблему освоения территорий, прилегающих к объектам культурного наследия и причинения в следствие этого вреда последним.

Однако, с принятием указанного закона возникает целый ряд проблем. В рамках настоящей статьи будет рассмотрен исключительно аспект, связанный с объектами археологического наследия.

Итак, при внимательном прочтении статьи 34.1 Закона об ОКН получается, что защитные зоны не устанавливаются для объектов археологи- 


\section{Административное и муниципальное право 6 (102) 2016}

ческого наследия. Возникают логичные вопросы почему и как быть?

Начинаем изучать данный вопрос и обращаемся за ответом, в первую очередь, к Министерству культуры РФ, которое и было инициатором принятия вышеназванного закона. И с удивлением узнаем, что позиция указанного министерства сводится к тому, что для объектов археологического наследия зоны охраны не нужны в принципе.

Так, в письмах Министерства культуры РФ от 29 декабря 2014 года № 3726-12-06 [9] и от 29 июня 2015 года № 2736-12-06 [10] об отказе в согласовании проекта зон охраны на памятник археологии «Городище «Семикаракорское» (Ростовская область) сообщается, что: «Проектирование зон охраны памятников истории и культуры является элементом градостроительного зонирования территории, которое прежде всего направлено на сохранение видового раскрытия исторических зданий и сооружений и сохранение исторической среды объектов культурного наследия. ... Таким образом, комплекс мер по государственной охране скрытых в земле объектов археологического наследия, обеспечивающий их сохранность, включает в себя установление границы его территории. ... Установление зон охраны для скрытых в земле объектов археологического наследия не представляется целесообразным.».

Указанная трактовка дается министерством исключительно из прочтения ст. 34 Закона об ОКН. При этом, естественно в данной статье ничего прямо не говорится о том, что для объектов археологического наследия или объектов, скрытых под землей, не устанавливаются зоны охраны. Не говорится об этом и в действующем Положении о зонах охраны объектов культурного наследия (памятников истории и культуры) народов Российской Федерации [11]. Т.е., трактовка министерства является исключительно субъективной.

Если обратиться к практике разрешения данного вопроса при СССР, то все в том же уже упомянутом Положении об охране и использовании памятников истории и культуры было четко сказано, что зоны охраны устанавливаются для обеспечения сохранности в том числе и «памятников археологии».

Это положение является и абсолютно логичным с точки зрения практики. Так, если мы откажемся от зон охраны для объектов археологического наследия, то получается, что проводить работы любого характера (особенно земляные и строительные) можно будет прямо в плотную к территории памятника. А ведь такие работы могут привести к его повреждению: сползанию в котлован и обрушению, затрагиванию культурного слоя, который случайно выявлен и не был включен в территорию памятника, порча тракторами, буль- дозерами и прочей тяжелой строительной техникой, складирование грунта (отвалов) и пр. Здесь также дополнительно нужно учитывать и сложность однозначного определения территории памятника для объектов археологического наследия. Ведь не для каждого памятника археологии в зависимости от его вида это возможно без проведения полноценных раскопок. Так, например, основной способ определения границ территории памятника археологии - это шурфовки. Вместе с тем, согласно Положению о порядке проведения археологических полевых работ и составлению научной отчетной документации [12], поведение шурфовок на памятниках археологии - курганах - строго запрещено. А учитывая, что насыпи курганов под влиянием времени (выветривание, распашка и т.д.) оплывают и растягиваются, а также могут иметь ровики и канавки, расположенные вокруг насыпи (на различном расстоянии), а также межкурганное пространство (между насыпями в одной курганной группе), то установить точную границу памятника не всегда возможно. И отсутствие зон охраны фактически приведет к их возможному повреждению. Аналогичным образом это может касаться и городища и грунтового могильника. И вообще не ясной будет ситуацию с крепостями, которые, как правило являются памятниками археологии, но совмещают в себе и архитектуру. Если же в данном случае, министерство исходит из фактора «скрытости под землей», то как его определить - многие крепости и городища фактически представляют собой земляные валы с элементами руин, выходящих наружу. Является ли это скрытым под землей или нет - вновь исключительно субъективное мнение. А ведь им защита от хозяйственной деятельности нужна не меньше чем памятникам архитектуры.

Основную остроту рассматриваемой проблеме в общем-то придают сразу 3 фактора:

- далеко не у всех объектов археологического наследия точно определена территория, в связи с чем не ясно какой размере земельного участка вокруг памятника археологии указывать в проектной документации, подаваемой на согласование;

- $\quad$ в связи с отменой СРП 2007 [13], в котором предусматривалась такая защитная мера как археологический надзор, проводимый в зоне строительных работ возле объектов археологического наследия, теперь еще и без зон охраны фактически становится невозможным обеспечение их сохранности вообще;

- учитывая что законодательно на федеральном уровне теперь введены защитные зоны временного характера и четко определено для каких объектов культурного наследия они устанавливаются, становится незаконным дальнейшее 
существование положений о временных охранных зонах в региональных законах, в том числе и в части объектов археологического наследия - что приводит к их отмене и следовательно оставлению объектов археологического наследия без какой-либо защиты в этой части.

Пытаясь разобраться в мотивах такой трактовки со стороны федеральных властей логичными выглядят предположения об отсутствии финансирования на разработку и установление зон охраны для них (ведь все объекты археологического наследия являются федеральными, а их количество по сравнению с иными объектами культурного наследия является подавляющим), а также невозможность установления ограничений произвольного характера на достаточно большое количество земельных участков и фактически их вывод из оборота (тяжелая социально-экономическая обстановка, недовольство людей).

Вместе с тем, полагаем что и просто устранять зоны охраны как вид мер по обеспечению сохран- ности объектов археологического наследия - недопустимо, это приведет к их бесконтрольному разрушению.

Видится, что введенные защитные зоны необходимо распространить на объекты археологического наследия с возможностью их уменьшения при разработке проектов зон охраны на основании комплексных научных исследований при появлении такого желания у заинтересованного лица (того, кто предполагает осваивать близлежащий земельный участок, который попадает в эту защитную зону). Либо, как вариант, установить в Законе об ОКН или вновь принятых ГОСТах, пришедших на смену СРП 2007, такую предупредительную охранную меру, как археологический надзор в случае, если проведение работ планируется в зоне объекта археологического наследия. При этом размеры зоны можно установить по примеру временных охранных зон, установленных в Краснодарском крае: в зависимости от вида памятника археологии и его размера [14].

\section{Библиография:}

1. Конституция Российской Федерации. Принята всенародным голосованием 12 декабря 1993 г. (с учетом поправок, внесенных Законами Российской Федерации о поправках к Конституции Российской Федерации от 30 декабря 2008 г. № 6-ФКЗ, от 30 декабря 2008 г. № 7-ФКЗ, от 05 февраля 2014 г. № 2-ФКЗ и от 21 июля 2014 г. № 11-ФКЗ) // Российская газета. 1993. 25 дек.; Собр. законодательства Рос. Федерации. 2014. № 31. Ст. 4398.

2. Об объектах культурного наследия (памятниках истории и культуры) народов Российской Федерации : Федеральный закон от 25 июня 2002 года № 73-ФЗ (в ред. от 05 апреля 2016 г. № 95-ФЗ) // Собр. законодательства Рос. Федерации. 2002. № 26. Ст. 2519; 2016. № 15. Ст. 2057.

3. Об охране и использовании памятников истории и культуры : Закон РСФСР от 15 декабря 1978 года // Свод законов РСФСР. Т. 3. С. 498.

4. Положением об охране и использовании памятников истории и культуры, утвержденным Постановлением Совета Министров СССР от 16 сентября 1982 г. N 865 // СП СССР. 1982. № 26. Ст. 133.

5. Инструкции о порядке учета, обеспечения сохранности, содержания, использования и реставрации недвижимых памятников истории и культуры: Приказ Минкультуры СССР от 13 мая 1986 г. № 203 // Текст официально опубликован не был. Текст доступен в СПС «Гарант».

6. Об утверждении Положения о зонах охраны объектов культурного наследия (памятников истории и культуры) народов Российской Федерации: Постановление Правительства РФ от 26 апреля 2008 года № 315 (утратило силу) // Собр. законодательства Рос. Федерации. 2008. № 18. Ст. 2053.

7. 0 землях недвижимых объектов культурного наследия (памятников истории и культуры) регионального и местного значения, расположенных на территории Краснодарского края, и зонах их охраны: Закон Краснодарского края от 06 июня 2002 года № 487-КЗ (утратил силу) // Кубанские новости. № 118-119. 19.06.2002.

8. $\quad$ В внесении изменений в Федеральный закон «Об объектах культурного наследия (памятниках истории и культуры) народов Российской Федерации» и статью 15 Федерального закона «О государственном кадастре недвижимости: Федеральный закон от 05 апреля 2016 года № 95-Ф3 // Собр. законодательства Рос. Федерации. 2016. № 15. Ст. 2057.

9. Письмо Министерства культуры РФ от 29 декабря 2014 года № 3726-12-06 // Текст документа официально не опубликован. Переписка Министерства культуры РФ и Министерства культуры Ростовской области.

10. Письмо Министерства культуры РФ от 29 июня 2015 года № 2736-12-06 // Текст документа официально не опубликован. Переписка Министерства культуры РФ и Министерства культуры Ростовской области.

11. Об утверждении Положения о зонах охраны объектов культурного наследия (памятников истории и культуры) народов Российской Федерации и о признании утратившими силу отдельных положений нормативных правовых актов Правительства Российской Федерации: Постановление Правительства РФ от 12 сентября 2015 года № 972 // Собр. законодательства Рос. Федерации. 2015. № 38. Ст. 5298.

12. Положению о порядке проведения археологических полевых работ и составлению научной отчетной документации: Постановление Бюро Отделения историко-филологических наук Российской академии наук от 27.11.2013 года № 85 // Размещено на официальном сайте Института археологии PAH. URL: http://www.archaeolog.ru (дата обращения - 07.06.2016).

13. Письмо Министерства культуры РФ от 27 августа 2015 года № 280-01-39-ГП // Размещено на официальном сайте Министерства культуры РФ. URL.: http://mkrf.ru (дата обращения - 07.06.2016). 
14. Об объектах культурного наследия (памятниках истории и культуры) народов Российской Федерации, расположенных на территории Краснодарского края: Закон Краснодарского края от 23 июля 2015 года № 3223-К3 // Официальный сайт администрации Краснодарского края. URL.: http://admkrai.krasnodar.ru (дата обращения-07.06.2016).

\section{References (transliterated):}

1. Konstitutsiya Rossiiskoi Federatsii. Prinyata vsenarodnym golosovaniem 12 dekabrya 1993 g. (s uchetom popravok, vnesennykh Zakonami Rossiiskoi Federatsii o popravkakh k Konstitutsii Rossiiskoi Federatsii ot 30 dekabrya 2008 g. № 6-FKZ, ot 30 dekabrya 2008 g. № 7-FKZ, ot 05 fevralya 2014 g. № 2-FKZ i ot 21 iyulya 2014 g. № 11-FKZ) // Rossiiskaya gazeta. 1993. 25 dek.; Sobr. zakonodatel'stva Ros. Federatsii. 2014. № 31. St. 4398.

2. Ob ob"ektakh kul'turnogo naslediya (pamyatnikakh istorii i kul'tury) narodov Rossiiskoi Federatsii : Federal'nyi zakon ot 25 iyunya 2002 goda № 73-FZ (v red. ot 05 aprelya 2016 g. № 95-FZ) // Sobr. zakonodatel'stva Ros. Federatsii. 2002. № 26. St. 2519; 2016. № 15. St. 2057.

3. Ob okhrane i ispol'zovanii pamyatnikov istorii i kul'tury : Zakon RSFSR ot 15 dekabrya 1978 goda // Svod zakonov RSFSR. T. 3. S. 498.

4. Polozheniem ob okhrane i ispol'zovanii pamyatnikov istorii i kul'tury, utverzhdennym Postanovleniem Soveta Ministrov SSSR ot 16 sentyabrya 1982 g. N 865 // SP SSSR. 1982. № 26. St. 133.

5. Instruktsii o poryadke ucheta, obespecheniya sokhrannosti, soderzhaniya, ispol'zovaniya i restavratsii nedvizhimykh pamyatnikov istorii i kul'tury: Prikaz Minkul'tury SSSR ot 13 maya 1986 g. № 203 // Tekst ofitsial'no opublikovan ne byl. Tekst dostupen v SPS «Garant».

6. Ob utverzhdenii Polozheniya o zonakh okhrany ob"ektov kul'turnogo naslediya (pamyatnikov istorii i kul'tury) narodov Rossiiskoi Federatsii: Postanovlenie Pravitel'stva RF ot 26 aprelya 2008 goda № 315 (utratilo silu) // Sobr. zakonodatel'stva Ros. Federatsii. 2008. № 18. St. 2053.

7. 0 zemlyakh nedvizhimykh ob"ektov kul'turnogo naslediya (pamyatnikov istorii i kul'tury) regional'nogo i mestnogo znacheniya, raspolozhennykh na territorii Krasnodarskogo kraya, i zonakh ikh okhrany: Zakon Krasnodarskogo kraya ot 06 iyunya 2002 goda № 487-KZ (utratil silu) // Kubanskie novosti. № 118-119. 19.06.2002.

8. 0 vnesenii izmenenii v Federal'nyi zakon «Ob ob"ektakh kul'turnogo naslediya (pamyatnikakh istorii i kul'tury) narodov Rossiiskoi Federatsii» i stat'yu 15 Federal'nogo zakona «0 gosudarstvennom kadastre nedvizhimosti: Federal'nyi zakon ot 05 aprelya 2016 goda № 95-FZ // Sobr. zakonodatel'stva Ros. Federatsii. 2016. № 15. St. 2057.

9. Pis'mo Ministerstva kul'tury RF ot 29 dekabrya 2014 goda № 3726-12-06 // Tekst dokumenta ofitsial'no ne opublikovan. Perepiska Ministerstva kul'tury RF i Ministerstva kul'tury Rostovskoi oblasti.

10. Pis'mo Ministerstva kul'tury RF ot 29 iyunya 2015 goda № 2736-12-06 // Tekst dokumenta ofitsial'no ne opublikovan. Perepiska Ministerstva kul'tury RF i Ministerstva kul'tury Rostovskoi oblasti.

11. Ob utverzhdenii Polozheniya o zonakh okhrany ob"ektov kul'turnogo naslediya (pamyatnikov istorii i kul'tury) narodov Rossiiskoi Federatsii i o priznanii utrativshimi silu otdel'nykh polozhenii normativnykh pravovykh aktov Pravitel'stva Rossiiskoi Federatsii: Postanovlenie Pravitel'stva RF ot 12 sentyabrya 2015 goda № 972 // Sobr. zakonodatel'stva Ros. Federatsii. 2015. № 38. St. 5298.

12. Polozheniyu o poryadke provedeniya arkheologicheskikh polevykh rabot i sostavleniyu nauchnoi otchetnoi dokumentatsii: Postanovlenie Byuro Otdeleniya istoriko-filologicheskikh nauk Rossiiskoi akademii nauk ot 27.11.2013 goda № 85 // Razmeshcheno na ofitsial'nom saite Instituta arkheologii RAN. URL: http://www.archaeolog.ru (data obrashcheniya 07.06.2016).

13. Pis'mo Ministerstva kul'tury RF ot 27 avgusta 2015 goda № 280-01-39-GP // Razmeshcheno na ofitsial'nom saite Ministerstva kul'tury RF. URL.: http://mkrf.ru (data obrashcheniya - 07.06.2016).

14. Ob ob"ektakh kul'turnogo naslediya (pamyatnikakh istorii i kul'tury) narodov Rossiiskoi Federatsii, raspolozhennykh na territorii Krasnodarskogo kraya: Zakon Krasnodarskogo kraya ot 23 iyulya 2015 goda № 3223-KZ // Ofitsial'nyi sait administratsii Krasnodarskogo kraya. URL.: http://admkrai.krasnodar.ru (data obrashcheniya-07.06.2016). 